\title{
Iron Uptake from Rat Plasma Transferrin
}

\section{by Rat Reticulocytes}

\author{
H. Huebers, E. Huebers, E. Csiba, and C. A. FinCH, Department of Medicine, Division \\ of Hematology, University of Washington, Seattle, Washington 98195
}

A B S T RACT Fast and slow rat transferrins were isolated by isoelectric focusing and prepared in their di- and monoferric forms. A comparison of the rates of iron release between fast and slow diferric transferrins and between fast and slow monoferric transferrins when incubated with reticulocytes or injected in vivo showed no significant difference in the behavior of the two isotransferrin species. Reticulocyte uptake of diferric transferrin resulted in the removal of both iron atoms from the transferrin molecule. A twofold greater iron uptake was observed from diferric as compared with monoferric iron, provided reticulocyte receptors were saturated. It is concluded that the two species of transferrin and their individual sites function similarly in their release of iron to tissue receptors.

\section{INTRODUCTION}

Transferrin is the iron transport protein of the blood plasma. Tracer studies of internal iron kinetics have been based on the assumption that transferrin iron behaves as a homogeneous iron pool $(1,2)$. In the past 10 years this concept has been questioned by a number of investigators on the basis of the chemical behavior of the two iron binding sites of the transferrin molecule (3-8), the uptake of transferrin iron by reticulocytes $(9,10)$, and in vivo studies of iron exchange (11-14). Most of the biologic studies supporting a heterogeneous behavior of transferrin iron have been carried out with materials from the rat. Rat plasma has two isotransferrins, referred to as transferrin-fast $\left(\mathrm{Tf}_{\mathrm{f}}\right)^{1}$ and transferrin-slow ${ }^{2}\left(\mathrm{Tf}_{\mathrm{s}}\right)$, which exist in apo-, mono-, and

Dr. Huebers was supported by a fellowship from the Deutsche Forschungsgemeinschaft.

Received for publication 21 February 1978 and in revised form 8 June 1978.

${ }^{1}$ Abbreviations used in this paper: $\mathrm{Tf}_{\mathrm{f}}$, transferrin-fast; $\mathrm{Tf}_{\mathrm{s}}$, transferrin-slow.

${ }^{2}$ The symbols $f$ and $s$ refer to the sequence of the diferric peaks in the eluate of a DEAE column at alkaline $\mathrm{pH}$ (15). This differs from the nomenclature of Gordon and Louis (16) where the electrophoretic mobility denoted by the symbols $S$ and $F$ was reversed. diferric forms (16). Heterogeneity in the delivery of iron could be a result of $(a)$ differences between isotransferrins, $(b)$ differences between the two binding sites of the transferrin molecule, $(c)$ the relative number of mono- and diferric transferrin molecules, or $(d)$ methodologic problems in a complex experimental model. These possibilities have been examined in this study, and the transport behavior of transferrin has been defined.

\section{METHODS}

Male Sprague-Dawley rats weighing $200-250 \mathrm{~g}$ were used throughout. Iron deficiency was produced by feeding rats a low-iron diet $(8 \mathrm{mg} / \mathrm{kg})$ along with bleeding a total of $6 \mathrm{ml}$ of blood by cardiac puncture over a period of 14 days.

Plasma used for labeling the individual transferrin forms was obtained from iron-deficient rats fasted overnight. The serum iron of these rats was $\cong 40 \mu \mathrm{g} / \mathrm{dl}$ and the total iron binding capacity $\cong 850 \mu \mathrm{g} / \mathrm{dl}$. To $75 \mathrm{ml}$ of plasma $25 \mathrm{ml} 1 \mathrm{M}$ Tris/HCl buffer (pH 8.3) was added. Next, ferrous ammonium sulfate $(750 \mu \mathrm{g} \mathrm{Fe}$ dissolved in $2 \mathrm{ml} 0.01 \mathrm{~N} \mathrm{HCl})$ was mixed with $75 \mu \mathrm{Ci}{ }^{59} \mathrm{Fe}$ (as ${ }^{59} \mathrm{FeSO}_{4}$, sp act $6-20 \mu \mathrm{Ci} / \mu \mathrm{g}$, dissolved in $0.5 \mathrm{M} \mathrm{HCl}$, New England Nuclear, Boston, Mass.) or with $225 \mu \mathrm{Ci}{ }^{55} \mathrm{Fe}$ (as ${ }^{55} \mathrm{FeSO}_{4}$, sp act $20-30 \mu \mathrm{Ci} / \mu \mathrm{g}$, dissolved in $0.5 \mathrm{M} \mathrm{HCl}$ ) from the same manufacturer. The added iron was sufficient to exceed the transferrin saturation by about $20 \%$, and the final $\mathrm{pH}$ was 8.1. Excess iron was removed as described below. The mixture was then incubated at $37^{\circ} \mathrm{C}$ for $30 \mathrm{~min}$. After cooling to $4^{\circ} \mathrm{C}$ the plasma was allowed to stand overnight at $4^{\circ} \mathrm{C}$.

Isolation procedures. $\mathrm{Tf}_{\mathrm{f}}$ and $\mathrm{Tf}_{\mathrm{s}}$ were isolated from the iron-saturated plasma by gel chromatography on Sepharose 6B (Pharmacia Fine Chemicals, Piscataway, N. J.), DEAE ion exchange chromatography on Sephadex A-50 (Pharmacia Fine Chemicals), and isoelectric focusing procedures. Details of the method have been described (15). The absorption ratio $A_{465}$ $\mathrm{A}_{280}$ for diferric transferrin was found to be 0.046 as reported elsewhere (17). With these isolation procedures $300 \mathrm{mg}$ of diferric $\mathrm{Tf}_{\mathrm{f}}$ and $128 \mathrm{mg}$ of diferric $\mathrm{Tf}_{\mathrm{s}}$ were obtained from 75 $\mathrm{ml}$ plasma of iron-deficient rats.

Monoferric transferrin species were isolated with the tagged diferric transferrin species $T f_{f}$ and $T f_{s}$ as starting material. The method takes advantage of the observation that one iron atom is released from the acid-labile binding site at pH 5.1 (17). To achieve this 100-mg aliquots of the diferric preparation dissolved in $50 \mathrm{ml}$ buffered saline (pH 7.4) were applied individually to Sephadex G-50 chromatography (column $2.5 \times 89.5 \mathrm{~cm}$, gel equilibrated with $0.25 \mathrm{M}$ acetate/ 
acetic acid buffer, pH 5.1; void volume, $145 \mathrm{ml}$ ). Elution was performed with the same buffer as taken for equilibration at $1 \mathrm{ml} / \mathrm{min}$. The ultraviolet absorption of the eluate was monitored continuously with a Uvicord II detector (Pharmacia Fine Chemicals). The ${ }^{59} \mathrm{Fe}$ or ${ }^{55} \mathrm{Fe}$ content of the collected fractions was measured. The protein fractions carrying ${ }^{59} \mathrm{Fe}$ or ${ }^{55} \mathrm{Fe}$ coming at the void volume were pooled and the $\mathrm{pH}$ was adjusted to 7.0 with solid sodium bicarbonate. After concentration by ultrafiltration (Amicon ultrafiltration cell 8MC, PM10 filter, Amicon Corp., Lexington, Mass.) to $6 \mathrm{ml}$ ( $14 \mathrm{mg}$ protein/ $\mathrm{ml}$ ), and the solution was stored at $4^{\circ} \mathrm{C}$. No redistribution of the iron was observed after 1 mo storage. The absorption ratio of each monoferric band after isoelectric focusing at $\mathrm{A}_{465} / \mathrm{A}_{280}$ was 0.023 , indicating an iron:protein ratio of $1: 1$ (17). In addition, no redistribution occurred between acid-labile and acid-stable sites as evidenced by repeating Sephadex G-50 chromatography at $\mathrm{pH}$ 5.1.

Selectively doubly labeled transferrin was prepared from the acid-stable, ${ }^{59} \mathrm{Fe}$-tagged, concentrated monoferric transferrin fraction after Sephadex G-50 chromatography at $\mathrm{pH}$ 5.1. The $\mathrm{pH}$ of $1 \mathrm{ml}$ of this fraction ( $14 \mathrm{mg}$ protein $/ \mathrm{ml}$ ) was raised to 8.0 with an equal volume of $0.3 \mathrm{M}$ Tris/ $\mathrm{HCl}$ buffer $(\mathrm{pH} 8.3)$. ${ }^{55} \mathrm{Fe}$-tagged ferrous ammonium sulfate (prepared as described above) was added in amounts sufficient to oversaturate the specific iron binding sites by $20 \%$ and allowing approximately equal counts of ${ }^{59} \mathrm{Fe}$ and ${ }^{55} \mathrm{Fe}$ iron. After a 30 -min incubation at $37^{\circ} \mathrm{C}$ a $2-\mathrm{ml}$ aliquot was applied on a Sephadex G-50 column $(1.8 \times 50 \mathrm{~cm})$ equlibrated with $0.3 \mathrm{M}$ Tris $/ \mathrm{HCl}$ buffer, $\mathrm{pH} 8.3$. Elution was performed with the same buffer at $0.5 \mathrm{ml} / \mathrm{min}$ and fractions of $5 \mathrm{ml}$ were collected. Three pooled radioiron containing fractions (vol, $15 \mathrm{ml}$ ) coming immediately after the void volume were found by isoelectric focusing to contain only specifically bound iron. Absorption spectroscopy gave a ratio $\mathrm{E}_{465} / \mathrm{E}_{280}$ of 0.046 which is characteristic for pure diferric rat plasma transferrin. Measurement of the ${ }^{55} \mathrm{Fe}:{ }^{59} \mathrm{Fe}$ ratio before and after passage through a Sephadex G-50 column at a $\mathrm{pH}$ of 5.1 provided evidence that the ${ }^{55} \mathrm{Fe}$ and ${ }^{59} \mathrm{Fe}$ were bound with a specificity of $84 \%$ to the acid-labile or acid-stable binding sites, respectively. In 10 different batches the specific localization was $86 \pm 5 \%$. No side-to-side exchange of the isotopes was observed during incubation and 1 -wk storage at $4^{\circ} \mathrm{C}$.

Before using the individual transferrin species for in vitro incubation with reticulocyte-rich suspensions or for intravenous injection in vivo, a 5-ml sample was buffer exchanged against Hanks' buffer (pH 7.4) with a column $(0.8 \times 20 \mathrm{~cm})$ filled with Sephadex G-25 coarse.

In vitro studies. Reticulocyte-rich suspensions were obtained from the heparinized blood of iron-deficient rats. These animals were bled through the abdominal aorta. The blood was centrifuged $(900 \mathrm{~g}, 10 \mathrm{~min})$ and the erythrocytes were washed once with a 10 -fold volume of $0.9 \%$ saline. Thereafter, the erythrocytes were resuspended in Hanks' buffer and divided in equal parts in preparation for incubation studies. After centrifugation, the supernate was replaced by a mixture of $1 \mathrm{ml}$ of the individually tagged transferrin species and 6 $\mathrm{ml}$ cold Hanks' buffer. Heparin (sodium salt) $(10 \mathrm{U} / \mathrm{ml})$ was added as an anticoagulant. The hematocrit was adjusted with Hanks' buffer to 15-20\%. Reticulocytes were stained with brilliant cresyl blue and counts of $\cong 40 \%$ were obtained. Incubation was performed for $60 \mathrm{~min}$ at $37^{\circ} \mathrm{C}$. Less than $3 \%$ of plasma radioactivity was found to be free hemoglobin. Duplicate samples of $400 \mu$ l were taken at various intervals between 0 and $60 \mathrm{~min}$ and centrifuged immediately at $4^{\circ} \mathrm{C}$ for $1 \mathrm{~min}$ at $7,900 \mathrm{~g}$. After centrifugation a $200-\mu \mathrm{l}$ aliquot of the supernate was removed and the erythrocytes were washed in $14 \mathrm{ml}$ of ice cold $0.9 \%$ saline ( $\mathrm{pH}$ adjusted to 7.4 with 20 $\mathrm{mM}$ phosphate buffer, pH 7.4). After centrifugation $(1,400 \mathrm{~g}$, $10 \mathrm{~min})$ the radioactivity in the reticulocyte-rich sediment was counted. Radioactivity in the incubation medium was counted in 200- $\mu$ l aliquots in an automatic $\gamma$-counter (Packard model 5330, Packard Instrument Co., Inc., Downers Grove, Ill.). Total plasma activity and total erythrocyte activity were calculated with the hematocrit. Iron uptake by reticulocytes was expressed as microgram iron taken up by $1 \mathrm{ml}$ of the reticulocyte-rich sediment in $1 \mathrm{~h}$. The iron uptake was plotted against the iron concentration in the incubation medium given as micrograms of $\mathrm{Fe}$ per deciliter media.

In vivo studies. In these studies $250-\mu \mathrm{l}$ samples of the tagged transferrin species (containing $0.5-1 \mu \mathrm{Ci}{ }^{59} \mathrm{Fe}$ or ${ }^{55} \mathrm{Fe}$; iron content $0.2 \mu \mathrm{g}$ ) were used for injection; $0.5 \mathrm{ml}$ of the mixture of two different diferric transferrin forms, each labeled with a separate isotope, was injected in the tail vein of the anesthetized animal. After $2 \mathrm{~min}$ a $0.5-\mathrm{ml}$ blood sample was taken by heart puncture and the radioactivity in a 200- $\mu$ l plasma aliquot was counted as described under In vitro studies. The activity of this plasma aliquot served as a $100 \%$ radioiron standard for monitoring the plasma radioiron disappearance. Iron-deficient rats were sacrificed $15 \mathrm{~min}$ after the injection of the diferric and $25 \mathrm{~min}$ after the injection of the monoferric transferrin samples. For normal rats the intervals were 40-60 min. These times gave tissue uptake of at least $50 \%$ of the injected isotopes.

At the time of sacrifice $7-8 \mathrm{ml}$ blood was removed through the abdominal aorta; $400-\mu$ l blood samples were immediately put on ice and centrifuged at $4{ }^{\circ} \mathrm{C}$. ${ }^{59} \mathrm{Fe}$ radioactivity in the sediment and in plasma aliquots was counted as described under In vitro studies. Meanwhile, the animal was exchange transfused with 2-3 blood vol of a $0.9 \%$ saline warmed up to $37^{\circ} \mathrm{C}$. The liver, femurs, and spleen were removed for determination of radioactivity. In one study heme was extracted from an aliquot of marrow and reticulocytes (18) and ferritin from liver (heat denaturation and ammonium sulfate precipitation).

${ }^{59} \mathrm{Fe}$ activity was measured at $4^{\circ} \mathrm{C}$ with a Packard $\gamma$-counter (model 5330, Packard Instrument Co., Inc.). Total plasma activity and total erythrocyte activity were calculated with the hematocrit and assuming a blood volume of $60 \mathrm{ml} / \mathrm{kg}$ body weight. Total marrow activity was calculated by multiplying the total activity in the two femurs by 6.5 .

Total ${ }^{55} \mathrm{Fe}$ activity was not determined directly but was derived from the count ratio of ${ }^{59} \mathrm{Fe}$ to ${ }^{55} \mathrm{Fe}$. Duplicate $0.2-$ $0.4-\mathrm{g}$ aliquots of organs and 200- $\mu$ l aliquots of plasma and erythrocytes were wet ashed. An aliquot of marrow was eluted from each femur with $0.2 \mathrm{ml}$ saline and this too was wet ashed. All samples were prepared for counting by a modification of the method of Eakins and Brown (19) and were counted in a Packard model 2425 Tri-Carb liquid scintillation spectrometer (Packard Instrument Co., Inc.). Counting efficiencies were $75 \%$ for ${ }^{59} \mathrm{Fe}$ and $25 \%$ for ${ }^{55} \mathrm{Fe}$. Correction was made for cross counting, and the ratio of ${ }^{55} \mathrm{Fe}:{ }^{59} \mathrm{Fe}$ was calculated. The injected transferrin samples were also counted and radioactivity was expressed as a percentage of the injected dose. Data was analyzed with Student's $t$ test.

Isoelectric focusing procedure. The purity of the individual transferrin forms and the distribution of ${ }^{99} \mathrm{Fe}$ between monoferric and diferric transferrin species was monitored by isoelectric focusing in gel columns. In these studies 2-ml samples were dialyzed against $1 \mathrm{mM}$ Tris/ $\mathrm{HCl}$ buffer $(\mathrm{pH} \mathrm{7.6)}$ and a $0.5-\mathrm{ml}$ aliquot was subjected to isoelectric focusing. A $7.5 \%$ polyacrylamide column $(1.4 \times 18 \mathrm{~cm})$ was prepared according to Karlsson et al. (20). The gel contained 1\% ampholine ( $\mathrm{pH}$ range 5-7; LKB Western Instruments, Pleasant Hill, Calif.), and isoelectric focusing was carried out in an electrophoresis cell (Bio-Rad model 155 Bio-Rad Laboratories, Richmond, Calif.) for $20 \mathrm{~h}$ at $1,000 \mathrm{~V}$ and $10^{\circ} \mathrm{C}$. Thereafter, the gel was cut into slices of $2-\mathrm{mm}$ thickness, altogether 
$\cong 90$ sections/gel. The radioiron content in these slices was measured in a gamma spectrometer (Packard model 5330 Packard Instrument Co., Inc.). In some studies the transferrin species were eluted out from the gel by addition of $3 \mathrm{ml}$ $0.1 \mathrm{M}$ Tris/ $\mathrm{HCl}$ buffer $(\mathrm{pH} 8.0)$ and shaken overnight at room temperature. A 2-ml aliquot was taken and the absorption ratio $\mathbf{A}_{465} / \mathbf{A}_{280}$ was determined with a Gilford spectrophotometer (model 2400, Gilford Instrument Laboratories, Inc., Oberlin, Ohio).

\section{RESULTS}

Analytical separation of the individual transferrin species (Fig. 1). Isoelectric focusing yielded a single visible band for the diferric species $\mathrm{Tf}_{f}$ and $\mathrm{Tf}_{\mathrm{s}}$. The isoelectric points were determined to be 5.7 for $\mathrm{Tf}_{f}$ and 5.6 for $\mathrm{Tf}_{\mathrm{s}}$. No cross contamination was observed. Elution of the protein from the gel and measurement of the absorption ratio $A_{465} / A_{280}$ gave a value of $0.046 \pm 0.001$.

After running the diferric species through a Sephadex G-50 ( $\mathrm{pH}$ 5.1), the acid $\mathrm{pH}$ of the column removed iron from the labile binding site of the transferrin molecule. This treatment gave rise to two different monoferric transferrin species staining equally for iron and for

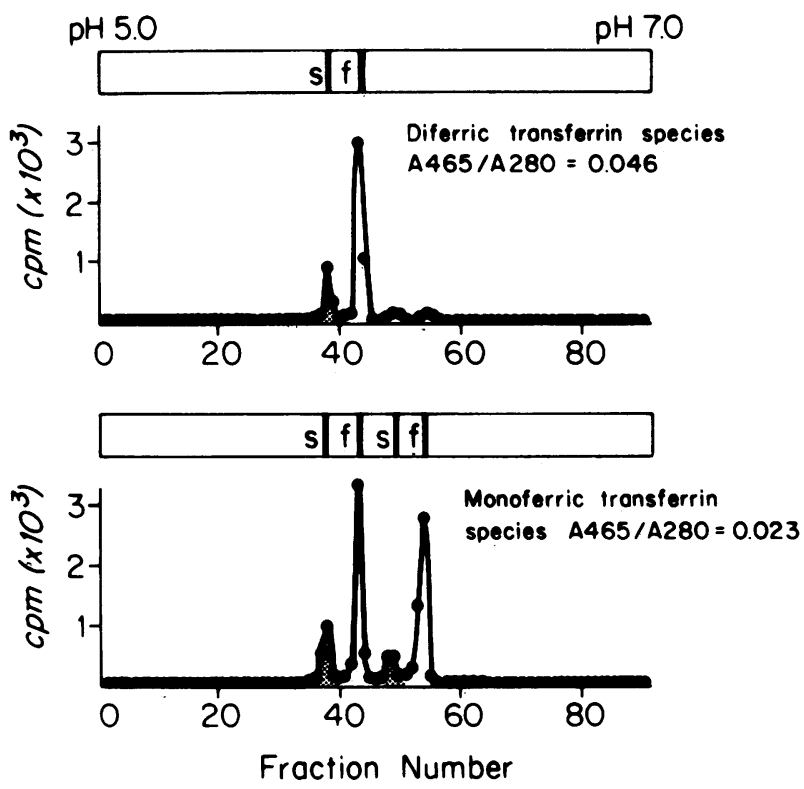

FIGURE 1 Isoelectric focusing pattern of rat plasma transferrin species. The gel was $1.4 \times 18 \mathrm{~cm}$, contained $1 \%$ ampholine, $\mathrm{pH}$ range 5-7, and was run for $20 \mathrm{~h}$ at $1,000 \mathrm{~V}$. The position of the visible peaks of $\mathrm{Fe}_{2} \mathrm{Tf}_{3}, \mathrm{Fe}_{2} \mathrm{Tf}_{\mathrm{f}}$, the two monoferric $\mathrm{Tf}_{8}$, and the two monoferric $\mathrm{Tf}_{\mathrm{f}}$ are indicated. After the isoelectric focusing run the gel was cut into slices of $2 \mathrm{~mm}$ thickness and the radioiron content was measured. (a) $\mathrm{Fe}_{2} \mathrm{Tf}_{\mathrm{8}}$ was labeled with ${ }^{55} \mathrm{Fe}$ (shaded area) and $\mathrm{Fe}_{2} \mathrm{Tf}_{\mathrm{f}}$ was labeled with ${ }^{59} \mathrm{Fe}$ (open area). (b) Same sample as in $a$ but after a $\mathrm{pH}$ step to 5.1 to produce the monoferric species. The species $\mathrm{Fe}_{2} \mathrm{Tf}_{\mathrm{f}}$ and $\mathrm{Fe}_{2} \mathrm{Tf}_{\mathrm{s}}$ were mixed in the ratio 70:30 as they occur normally in the plasma of iron-deficient rats. The radioactive counts of ${ }^{55} \mathrm{Fe}$ and ${ }^{59} \mathrm{Fe}$ per milligram transferrin were similar. protein for each of the two diferric forms. The monoferric bands ranged from $\mathrm{pH}$ 5.6 to 6.2. The absorption ratio $A_{465} / A_{280}$ for material eluted from the individual bands gave values of $0.023 \pm 0.001$.

In vitro studies. The iron uptake from the two ${ }^{59} \mathrm{Fe}-$ tagged diferric transferrins at a mixture as they occur in the plasma of iron-deficient rats (70:30) was found to be concentration dependent and gave a curve with saturation characteristics (Fig. 2). A similar shape was found for the uptake of iron from a mixture of the four monoferric species (Fig. 2). The amount of iron taken up from the two iron-loaded forms was similar up to an iron concentration of $40 \mu \mathrm{g} / \mathrm{dl}$. At higher concentrations of iron precisely twice as much iron is taken up from the diferric form. The ${ }^{59} \mathrm{Fe}$ isoelectric focusing profile of the diferric species at an iron concentration of $90 \mu \mathrm{g} / \mathrm{dl}$ before and after reticulocyte incubation is shown in Fig. 3. The profile of the incubation medium containing only diferric transferrin ( $s$ and $f$ ) is shown on the left. Monoferric species are present only in tracer amounts. This same plasma after reticulocyte incubation is shown on the right. After the 60 -min incubation period about one-half of the iron is removed by the reticulocytes, and there is no appearance of appreciable amounts of the monoferric species. It is also evident that iron is removed proportionately from $\mathrm{Tf}_{\mathrm{f}}$ and $\mathrm{Tf}_{\mathrm{s}}$ because the distribution of radioiron between the two diferric species before and after incubation stays constant.

In addition, the iron donating properties of the

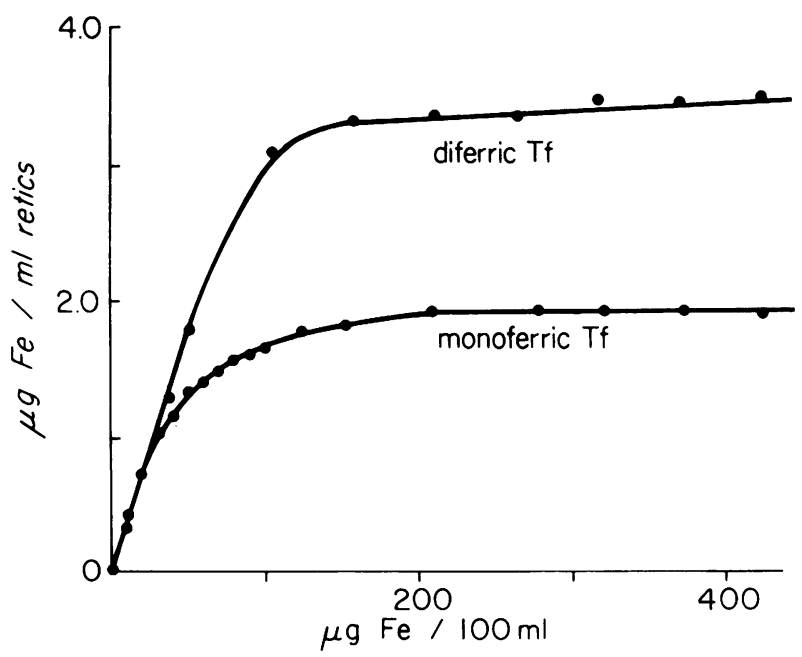

FIGURE 2 Iron uptake by reticulocytes (retics) as a function of the iron concentration of monoferric and diferric transferrinbound iron. Iron concentration of the media was varied by the addition of purified mono- and diferric transferrin and was incubated with a constant number of reticulocytes obtained from iron-deficient blood and suspended in Hanks' buffer at a hematocrit of 15-20\%. The incubation was carried out for 60 min at $37^{\circ} \mathrm{C}$. Each point is the mean of six individual determinations. 


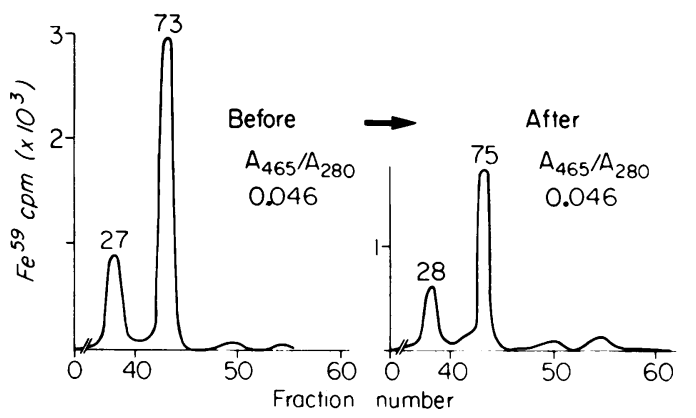

FIGURE 3 Isoelectric focusing pattern of ${ }^{59} \mathrm{Fe}$-tagged $\mathrm{Fe}_{2} \mathrm{Tf}_{\mathrm{f}}$ and $\mathrm{Fe}_{2} \mathrm{Tf}_{\mathrm{s}}$ species before and after incubation with reticulocytes. Reticulocytes from iron-deficient rats were incubated for $60 \mathrm{~min}$ at $37^{\circ} \mathrm{C}$. The initial iron concentration in the incubation medium was $90 \mu \mathrm{g} / \mathrm{dl}$. Isoelectric focusing was carried out with a 5-ml cell-free aliquot as described under Methods except that a fivefold concentration of the incubation media was employed. The distribution of the activity in percent between the fast and slow species as well as the absorption ratio of the peaks after isoelectric focusing is indicated.

diferric species fast and slow were compared separately. In incubation studies performed with six different reticulocyte populations from iron-deficient animals there was no significant difference in the rate of iron uptake between the pure species and their 50:50 mixture (Table I).

In vivo studies. To assess the behavior of the two diferric transferrin species in vivo, the two forms, each labeled with a separate isotope, were injected intravenously at the same time in normal and iron-deficient rats. After at least $50 \%$ of the plasma radioactivity had disappeared (15-40 min), the animal was perfused and tissue activity was determined (Table II). In the erythron and in other tissues there was no appreciable difference between the diferric species fast and slow as studied in iron-deficient and normal animals. A similar experiment done with the individual monoferric species derived from diferric fast and slow also showed no difference in the organ distribution. The isotope

TABLE I

Comparison of Reticulocyte Iron Uptake from the Diferric Transferrin Species Fast and Slow and their Mixture

\begin{tabular}{|c|c|c|c|}
\hline \multicolumn{4}{|c|}{ Reticulocyte iron uptake from diferric transferrin } \\
\hline $\mathbf{T f}_{\mathrm{f}}$ & & $\mathbf{T f}_{\mathrm{s}}$ & 50:50 mixture \\
\hline \multicolumn{4}{|c|}{$\mu g{ }^{\mathrm{so}} \mathrm{Fe} / \mathrm{ml} / \mathrm{h}$} \\
\hline $\begin{array}{c}3.6 \pm 0.2 \\
(n=6)\end{array}$ & & $\begin{array}{c}3.3 \pm 0.2 \\
(n=6)\end{array}$ & $\begin{array}{c}3.4 \pm 0.15 \\
(n=5)\end{array}$ \\
\hline & NS & & \\
\hline
\end{tabular}

Conditions: iron concentration in the incubation medium before incubation $=200 \mu \mathrm{g} / \mathrm{dl}$; incubation was for $60 \mathrm{~min}$ at $37^{\circ} \mathrm{C}$ (hematocrit, 15-20\%). ratios from these experiments are given in Table III. All ratios are very close to one. The small differences found are not statistically significant $(P>0.05)$. In five normal animals heme was extracted from reticulocytes and marrow and ferritin from liver. Activity ratios obtained showed no significant difference from those found in the original tissue.

In the last experiment of this series the iron donating properties of the two iron binding sites in the diferric transferrin molecule were compared. One isotope $\left({ }^{59} \mathrm{Fe}\right)$ was bound specifically to the acid-stable binding side ("B side"), the other $\left({ }^{55} \mathrm{Fe}\right)$ to the acid-labile binding side ("A side"). The tissue distribution (Table IV) looks identical to the radioiron distribution of the uniformly labeled diferric species (Table II). Measurement of the ratio ${ }^{59} \mathrm{Fe}:{ }^{55} \mathrm{Fe}$ in tagged tissues of normal and iron-deficient rats (Table V) gave values very near to one, showing that the iron at either binding site is equally available for tissue uptake.

\section{DISCUSSION}

Transferrin is the pivotal molecule in internal iron metabolism, disbursing iron to tissues with widely different iron requirements. Exactly how this protein functions has been a matter of considerable interest (21-25), and alternate possibilities have been suggested. One is that the protein is able to pass iron selectively from its individual sites to site-specific tissues and by differential loading and unloading to direct the flow of iron (26). The other possibility is that transferrin acts as a general transport vehicle and that the exchange of iron is dictated by the amount of iron entering the circulation and the amount removed by individual tissues according to the number of receptors for iron which they possess. A clear definition of the behavior of transferrin would appear essential for an understanding of the regulation of the iron supply to individual tissues and for the interpretation of plasma iron kinetic studies.

The rat is a complex model, having two species of transferrin (15). $\mathrm{Tf}_{\mathrm{f}}$ constitutes $80 \%$ of all transferrin in the normal and $70 \%$ in the iron-deficient animal (17). In the present study these transferrins were isolated in pure form and as the mono- and diferric species. The majority of studies considered the simpler interaction of transferrin iron in these different forms with the receptors of immature rat erythrocytes. Other studies, however, evaluated the rate and amount of iron uptake from these transferrin fractions by body tissues in vivo.

The first question addressed was the comparative behavior of the two sites of transferrin. Fletcher and Huehns (26) advanced the hypothesis that each iron binding site of transferrin delivered iron preferentially to certain tissues, site $A$ to the erythron and placenta, and site $B$ to the liver and other tissues. Since that time 
TABLE II

Radioiron Content of Tissues after Intravenous Injection of Diferric Transferrin Fast and Slow

\begin{tabular}{|c|c|c|c|c|c|c|c|c|}
\hline \multirow[b]{2}{*}{ Recipient animal } & \multirow{2}{*}{$\begin{array}{l}\text { Species } \\
\text { injected }\end{array}$} & \multirow[b]{2}{*}{ Time } & \multicolumn{6}{|c|}{ Radioiron content (mean $\pm S D$ of injected dose) } \\
\hline & & & Blood & Plasma & Erythrocytes & Skeleton & Spleen & Liver \\
\hline & & $\min$ & & & & & & \\
\hline Iron-deficient $(n=6)$ & $\begin{array}{l}{ }^{59} \mathrm{Fe}_{2} \mathrm{Tf}_{\mathrm{s}} \\
{ }^{55} \mathrm{Fe}_{2} \mathrm{Tf}_{\mathrm{f}}\end{array}$ & 15 & $\begin{array}{l}55.8 \pm 2.0 \\
56.4 \pm 2.2\end{array}$ & $\begin{array}{l}28.6 \pm 0.9 \\
26.7 \pm 0.8\end{array}$ & $\begin{array}{l}27.2 \pm 0.4 \\
29.3 \pm 0.4\end{array}$ & $\begin{array}{l}19.2 \pm 1.2 \\
19.4 \pm 1.0\end{array}$ & $\begin{array}{l}3.0 \pm 0.9 \\
3.1 \pm 0.9\end{array}$ & $\begin{array}{l}17.5 \pm 3.8 \\
18.8 \pm 4.1\end{array}$ \\
\hline Normal $(n=6)$ & $\begin{array}{l}{ }^{59} \mathrm{Fe}_{2} \mathrm{Tf}_{\mathrm{s}} \\
{ }^{55} \mathrm{Fe}_{2} \mathrm{Tf}_{\mathrm{f}}\end{array}$ & 40 & $\begin{array}{l}45.5 \pm 1.3 \\
42.9 \pm 1.2\end{array}$ & $\begin{array}{l}30.7 \pm 1.9 \\
27.9 \pm 1.7\end{array}$ & $\begin{array}{l}14.8 \pm 0.6 \\
15.4 \pm 0.6\end{array}$ & $\begin{array}{l}26.2 \pm 2.4 \\
26.7 \pm 2.5\end{array}$ & $\begin{array}{l}4.0 \pm 0.7 \\
4.1 \pm 1.0\end{array}$ & $\begin{array}{l}7.2 \pm 1.5 \\
7.5 \pm 1.6\end{array}$ \\
\hline Iron-deficient $(n=3)$ & $\begin{array}{l}{ }^{59} \mathrm{Fe}_{1} \mathrm{Tf}_{\mathrm{s}} \\
{ }^{55} \mathrm{Fe}_{1} \mathrm{Tf}_{\mathrm{f}}\end{array}$ & 25 & $\begin{array}{l}56.3 \pm 4.2 \\
55.2 \pm 4.1\end{array}$ & $\begin{array}{l}40.4 \pm 1.2 \\
39.6 \pm 2.9\end{array}$ & $\begin{array}{l}15.9 \pm 1.1 \\
15.6 \pm 1.1\end{array}$ & $\begin{array}{l}14.6 \pm 2.6 \\
14.6 \pm 2.6\end{array}$ & $\begin{array}{l}3.5 \pm 1.5 \\
3.5 \pm 1.5\end{array}$ & $\begin{array}{l}11.0 \pm 2.5 \\
11.0 \pm 2.5\end{array}$ \\
\hline Normal $(n=3)$ & $\begin{array}{l}{ }^{59} \mathrm{Fe}_{1} \mathrm{Tf}_{\mathrm{s}} \\
{ }^{55} \mathrm{Fe}_{1} \mathrm{Tf}_{\mathrm{f}}\end{array}$ & 60 & $\begin{array}{l}45.9 \pm 5.3 \\
42.5 \pm 4.9\end{array}$ & $\begin{array}{l}35.5 \pm 0.4 \\
32.9 \pm 3.7\end{array}$ & $\begin{array}{r}10.4 \pm 0.2 \\
9.6 \pm 1.1\end{array}$ & $\begin{array}{l}23.8 \pm 3.0 \\
24.5 \pm 3.1\end{array}$ & $\begin{array}{l}3.9 \pm 1.3 \\
4.0 \pm 1.3\end{array}$ & $\begin{array}{l}3.6 \pm 0.4 \\
3.5 \pm 0.4\end{array}$ \\
\hline
\end{tabular}

a number of publications have reported confirming data (9-14). Such studies were based upon a model in which it was assumed that reticulocytes incubated with plasma would remove iron selectively from the socalled "reticulocyte-oriented site." In the present study it has been shown that the two isotopes of radioiron, added selectively by $\mathrm{pH}$ manipulation in vitro to the two sites of transferrin, were taken up in equal amounts by rat reticulocytes (Table IV). Similar results have been obtained by us in rabbit and human transferrinreticulocyte systems. The explanation for this identical uptake from the two sites was found when the residual plasma in the incubation system was examined. At a time when reticulocytes had removed approximately one-half of the iron from the media originally containing diferric transferrin, only diferric iron remained. This indicated that the transferrin molecule interacting with the erythroid cell loses all of its iron, and the model of reticulocyte incubation employed in the FletcherHuehns hypothesis which presumed a differential removal of iron from one site, was invalid. Here a distinction needs to be made between studies of iron exchange with chemical reagents such as nitrilotriacetic acid, DFO, phosphate compounds, etc., and the exchange that occurs with tissue receptors. It is clear that differences may be observed in in vitro systems of iron exchange involving chemical agents $(4,27$, 28). However, these are not relevant to the exchange of transferrin iron with tissue receptors.

Iron release from the $\mathrm{Tf}_{\mathrm{f}}$ and $\mathrm{Tf}_{\mathrm{s}}$ of the rat were also examined as a possible cause of heterogeneity in iron release. The comparative rates of release from the two diferric transferrins to reticulocytes in vitro (Table I) showed no significant difference as had previously

TABLE III

Radioiron Uptake Ratios from Slow/Fast Transferrin

\begin{tabular}{|c|c|c|c|c|}
\hline & \multicolumn{2}{|c|}{$\begin{array}{l}\text { Diferric transferrin species } \\
\text { ratio }{ }^{50} \mathrm{Fe}_{2} \mathrm{Tf}_{3} /{ }^{s} \mathrm{Fe}_{2} \mathrm{Tf}_{4}\end{array}$} & \multicolumn{2}{|c|}{$\begin{array}{l}\text { Monoferric transferrin species } \\
\text { ratio }{ }^{s 0} \mathrm{Fe}_{1} \mathrm{Tf}_{s} /{ }^{/ 5} \mathrm{Fe}_{1} \mathrm{Tf}_{f}\end{array}$} \\
\hline & Normal & Iron-deficient & Normal & Iron-deficient \\
\hline \multicolumn{5}{|l|}{ Erythron } \\
\hline Skeleton & $0.98 \pm 0.01$ & $0.99 \pm 0.04$ & $0.97 \pm 0.04$ & $1.00 \pm 0.02$ \\
\hline Marrow heme & $0.96 \pm 0.02$ & & & \\
\hline Erythrocytes & $0.96 \pm 0.03$ & $0.93 \pm 0.05$ & $0.94 \pm 0.06$ & $0.97 \pm 0.03$ \\
\hline Erythrocyte heme & $0.94 \pm 0.02$ & & & \\
\hline \multicolumn{5}{|l|}{ Other tissues } \\
\hline Liver & $0.96 \pm 0.02$ & $0.93 \pm 0.03$ & $1.02 \pm 0.04$ & $1.00 \pm 0.04$ \\
\hline Liver ferritin & $0.98 \pm 0.01$ & & & \\
\hline Spleen & $0.97 \pm 0.02$ & $0.98 \pm 0.03$ & $0.98 \pm 0.03$ & $1.01 \pm 0.03$ \\
\hline \multirow[t]{2}{*}{ Spleen ferritin } & $0.96 \pm 0.01$ & & & \\
\hline & \multicolumn{2}{|c|}{$(n=6)$} & \multicolumn{2}{|c|}{$(n=3)$} \\
\hline
\end{tabular}

Significance that the values are different from $1, P>0.05$ for all comparisons. Values are mean $\pm S D$. 
TABLE IV

Radioiron Content of Tissues after Injection of Transferrin whose Site B was Labeled with ${ }^{59} \mathrm{Fe}$ and Site A with ${ }^{55} \mathrm{Fe}$

\begin{tabular}{|c|c|c|c|c|c|c|c|c|}
\hline \multirow[b]{2}{*}{ Recipient animal } & \multirow{2}{*}{$\begin{array}{c}\text { Species } \\
\text { injected }\end{array}$} & \multirow[b]{2}{*}{ Time } & \multicolumn{6}{|c|}{ Radioiron content (mean $\pm \mathrm{SD}$ of injected dose, $n=4$ ) } \\
\hline & & & Blood & Plasma & Erythrocytes & Skeleton & Spleen & Liver \\
\hline & & $\min$ & & & & & & \\
\hline \multirow[t]{2}{*}{ Iron-deficient } & $\mathrm{B}^{59} \mathrm{Tf}_{\mathrm{f}}^{*}$ & 15 & $57.2 \pm 6.6$ & $28.4 \pm 3.3$ & $28.8 \pm 3.3$ & $20.1 \pm 1.8$ & $4.4 \pm 1.3$ & $13.0 \pm 1.2$ \\
\hline & $A^{55} T_{f}$ & 15 & $53.0 \pm 6.1$ & $25.6 \pm 3.0$ & $30.3 \pm 3.5$ & $20.3 \pm 1.8$ & $4.4 \pm 1.3$ & $13.1 \pm 1.2$ \\
\hline \multirow[t]{2}{*}{ Normal } & $\mathrm{B}^{59} \mathrm{Tf}_{\mathrm{f}}$ & 40 & $49.0 \pm 2.3$ & $30.3 \pm 1.4$ & $18.8 \pm 0.9$ & $28.0 \pm 9.3$ & $3.3 \pm 0.5$ & $4.3 \pm 0.9$ \\
\hline & $\mathrm{A}^{55} \mathrm{Tf}_{\mathrm{f}}$ & 40 & $45.0 \pm 2.1$ & $27.3 \pm 1.3$ & $19.6 \pm 0.9$ & $30.1 \pm 10.0$ & $3.5 \pm 0.5$ & $4.6 \pm 1.0$ \\
\hline
\end{tabular}

${ }^{*} \mathrm{~B}^{59} \mathrm{Tf} f_{\mathrm{f}}$ refers to a tag placed on the acid-stable site, whereas $\mathrm{A}^{55} \mathrm{Tf}_{\mathrm{f}}$ refers to a second isotope on the acid-labile site.

been stated by van Eijk (29). Further in vivo studies employing the two diferric transferrins labeled with different isotopes of iron (Table II) showed again similar rates of tissue uptake. Monoferric $\mathrm{Tf}_{\mathrm{f}}$ versus monoferric $\mathrm{Tf}_{\mathrm{s}}$ also showed ratios of about 0.96 in erythroid and nonerythroid tissues of normal and irondeficient animals (Table III). It was of interest that in most of these studies $\mathrm{Tf}_{\mathrm{f}}$ showed a slightly more rapid release amounting to $\cong 5 \%$ more than diferric transferrin. It seems unlikely that this very small difference, of questionable statistical significance, would have any physiologic meaning. More important, no difference was observed in the distribution of iron released to erythroid and nonerythroid tissues, even when the ratios of the two isotopes in tissue heme and ferritin were examined.

The conspicuous difference observed was in the rate of iron uptake between diferric and monoferric transferrin iron. It has been demonstrated by some investigators $(12,30,31)$, but not all $(32)$, that iron release from transferrin increases with increasing degrees of transferrin saturation, and it has been further shown that this is because of the greater proportion of diferric as compared to monoferric iron present $(33,34)$. In the reticulocyte model the diferric form can deliver precisely twice as much iron as the monoferric, providing there is sufficient transferrin present to saturate reticulocyte binding sites (Fig. II). However, this preferential capability of iron from diferric transferrin would seem to depend upon the saturation of reticulocyte receptors by transferrin iron complexes; at low iron concentrations the iron donating properties of pure diferric and monoferric suspensions to reticulocytes (in vitro) were found to be identical. In examining these effects, the biochemical and functional integrity of the transferrin preparations used is essential. Biochemical characteristics of the materials used in this study have been described, and radioiron turnover measurements in vivo (to be published elsewhere) were identical in their behavior to that of labeled plasma.

In reviewing previous reports of heterogeneity in the functional behavior of transferrin, several things appear to have been responsible. First, many of the earlier experiments that appeared to confirm the FletcherHuehns hypothesis were performed with rabbit reticulocytes and human transferrin, an unphysiologic system (35). More recent experiments have failed to show any difference in iron delivery from the two sites of rabbit transferrin to rabbit reticulocytes and from the two sites of human transferrin to human reticulocytes (36). Second, some investigators have used methods of adding radioactive iron to transferrin which is likely to lead to some degree of nonspecific binding to the transferrin molecule (37). Third, it has generally been assumed that when iron is added to transferrin in vitro that the iron binds randomly to free iron binding sites. It is becoming apparent that this is not always true, especially when the iron is added as its complex with nitrilotriacetic acid or citrate (4). A fourth problem has been the hemolysis that occurs in studies in which transferrin was preincubated with reticulocytes to remove some of the iron. This hemolysate contained radioactive hemoglobin which was preferentially removed by the liver and, therefore, altered tissue uptake ratios (38). Fifth, differences observed could relate to different amounts of mono- and diferric transferrin rather than to differences in the function of the two

TABLE V

Radioiron Uptake Ratios in Animals Injected with Transferrin Labeled with a Different Isotope at each Iron Binding Site (see Table IV)

\begin{tabular}{|c|c|c|}
\hline & \multicolumn{2}{|c|}{ Ratio ${ }^{50} \mathrm{Fe} /{ }^{55} \mathrm{Fe}$} \\
\hline & Normal & Iron-deficient \\
\hline \multicolumn{3}{|l|}{ Erythron } \\
\hline Skeleton & $0.93 \pm 0.01(n=4)$ & $0.99 \pm 0.03(n=4)$ \\
\hline Erythrocytes & $0.96 \pm 0.01(n=4)$ & $0.95 \pm 0.03(n=4)$ \\
\hline \multicolumn{3}{|l|}{ Other tissues } \\
\hline Liver & $0.93 \pm 0.01(n=4)$ & $0.99 \pm 0.01(n=4)$ \\
\hline Spleen & $0.95 \pm 0.01(n=4)$ & $0.99 \pm 0.03(n=4)$ \\
\hline
\end{tabular}


sites. A sixth possibility may be the use of commercial transferrin preparations without proper tests of the physiological integrity of the protein. The latter is best evaluated by comparison of the in vivo clearance of radioiron from the test material with that of native plasma transferrin. This may have been of particular importance in experiments with human transferrin because this protein is available from several different commercial sources, some of which show heterogeneous profiles by isoelectric focusing. A seventh possibility is the presence of EDTA in purified apotransferrin preparations (39). Experience has shown that extended dialysis, lasting days, may not free the protein preparation of traces of EDTA. Results of a given experiment ascribed to the iron from transferrin may be a result, in part, of iron-EDTA. Artefact may also be introduced by nitrilotriacetic acid as an iron chelating agent (38).

There are implications of these studies in respect to the behavior of the plasma iron pool. Whereas the two sites of transferrin and the two species of transferrin in the rat have been shown to be functionally equivalent, conspicuous differences in amount result from changes in the proportion of di- and monoferric transferrin. These observations are consistent with a general relationship between plasma iron and plasma-iron turnover which has been previously described (40) and which may now be assumed to be a function of the relative amounts of mono- and diferric transferrin present. One may conclude that the general concept of a single plasma iron pool employed in ferrokinetic measurements will need also to include a quantitative correction for the amount of mono- and diferric transferrin in that pool.

\section{ACKNOWLEDGMENTS}

This work was supported in part by National Institutes of Health grant HL-06242.

\section{REFERENCES}

1. Finch, C. A., K. Deubelbeiss, J. D. Cook, J. W. Eschbach, L. A. Harker, D. D. Funk, G. Marsaglia, R. S. Hillman, S. Slichter, J. W. Adamson, A. Ganzoni, and E. R. Giblett. 1970. Ferrokinetics in man. Medicine (Baltimore). 49: $17-53$.

2. Cavill, I., and C. Ricketts. 1974. The kinetics of iron metabolism. In Iron in Biochemistry and Medicine. A. Jacobs and M. Worwood, editors. Academic Press, Inc., New York. 613-647.

3. Lestas, A. N. 1976. The effect of pH upon human transferrin: selective labeling of the two iron-binding sites. Br. J. Haematol. 32: 341-350.

4. Harris, D. C. 1977. Different physical properties and similar functional properties of the two sites of human transferrin. In Proteins of Iron Metabolism. E. B. Brown, P. Aisen, J. Fielding, and R. R. Crichton, editors. Grune \& Stratton, Inc., New York. 197-204.
5. Price, E. M., and J. F. Gibson. 1972. Electron paramagnetic resonance evidence for a distinction between the two iron-binding sites in transferrin and conalbumin. J. Biol. Chem. 247: 8031-8035.

6. Lane, R. S. 1975. Differences between human Fe $\mathrm{F}_{1}$-transferrin molecules. Br. J. Haematol. 29: 511-520.

7. Donovan, J. W., and K. D. Ross. 1975. Iron binding to conalbumin. Calorimetric evidence for two distinct species with one bound iron atom. J. Biol. Chem. 250: 6026-6031.

8. Cannon, J. D., and N. D. Chasteen. 1975. Nonequivalence of the metal binding sites in vanadyl-labeled human serum transferrins. Biochemistry. 14: 4573-4577.

9. Fletcher, J. 1969. Variation in the availability of transferrin-bound iron for uptake by immature cells. Clin. Sci. (Oxf.). 37: 273-297.

10. Ganzoni, A. M., D. Hahn, and B. Spati. 1972. Plasma iron transport: absence of a uniform system. Blut. 24: 269-273.

11. Hahn, C. 1973. Functional behavior of transferrin. Eur. J. Biochem. 34: 311-316.

12. Hahn, D., B. Baviera, and A. M. Ganzoni. 1975. Functional heterogeneity of transport iron compartment. I. In vivo radioiron clearance from high and low saturated transferrin. Acta Haematol. (Basel). 53: 285-291.

13. Awai, M., B. Chipman, and E. B. Brown. 1975. In vivo evidence for the functional heterogeneity of transferrinbound iron. I. Studies in normal rats.J. Lab. Clin. Med. 85: 769-784.

14. Awai, M., B. Chipman, and E. B. Brown. 1975. In vivo evidence for the functional heterogeneity of transferrinbound iron. II. Studies in pregnant rats. J. Lab. Clin. Med. 85: 785-796.

15. Huebers, H., E. Huebers, W. Rummel, and R. R. Crichton. 1976. Isolation and characterization of iron binding proteins from rat intestinal mucosa. Eur. J. Biochem. 66: 447-455.

16. Gordon, A. H., and L. N. Louis. 1963. Preparation and properties of rat transferrin. Biochem. J. 88: 409-414.

17. Huebers, H., E. Huebers, S. Linck, and W. Rummel. 1977. A study of plasma transferrin in normal and iron deficient rats. In Proteins of Iron Metabolism. E. B. Brown, P. Aisen, J. Fielding, and R. R. Crichton, editors. Grune \& Stratton, Inc., New York. 251-260.

18. Labbe, R. F., and G. Nishida. 1957. A new method of hemin isolation. Biochim. Biophys. Acta. 26: 437.

19. Eakins, J. D., and E. A. Brown. 1966. An improved method for the simultaneous determination of iron 55 and iron 59 in blood by liquid scintillation counting. Int. J. Appl. Radiat. Isot. 17: 391-397.

20. Karlsson, C., H. Davies, J. Ohman, and U. B. Andersson. 1973. LKB 21-17 Multithor. I. Analytical thin layer gel electrofocusing in polyacrylamide gel. Application note 75, LKB-Produkter AB, Bromma, Sweden. 1-14.

21. Katz, J. H. 1970. Transferrin and its function in the regulation of iron metabolism. In Regulation of Hematopoiesis. A. S. Gordon, editor. Appleton-Century-Crofts, New York. 1: 539-577.

22. Zschocke, R. H., and A. Bezkorovainy. 1974. Structure and function of transferrins. II. Transferrin and iron metabolism. Arzneim-Forsch. 24: 726-737.

23. Morgan, E. H. 1974. Transferrin and transferrin iron. In Iron in Biochemistry and Medicine. A. Jacobs and M. Worwood. editors. Academic Press, Inc., New York. 29-71.

24. Lane, R. S. 1976. Transferrin. In Structure and Function of Plasma Proteins. A. C. Allison, editor. Plenum Publishing Corp., New York. 2: 53-78.

25. Aisen, P., and E. B. Brown. 1977. The iron-binding func- 
tion of transferrin in iron metabolism. Semin. Hematol. 14: 31-53.

26. Fletcher, J., and E. R. Huehns. 1968. Function of transferrin. Nature (Lond.). 218: 1211-1218.

27. Donovan, J. W., and K. D. Ross. 1976. Calorimetric studies of the binding of iron and aluminum to human serum transferrin. Fed. Proc. 35: 1608 (Abstr.)

28. Morgan, E. H. 1977. Iron release from transferrin mediated by organic phosphate compounds. In Proteins of Iron Metabolism. E. B. Brown, P. Aisen, J. Fielding, and R. R. Crichton, editors. Grune \& Stratton, Inc., New York. 227-236.

29. Van Eijk, H. G., and W. L. Van Noort. 1976. Isolation of rat transferrin using CNBr-activated Sepharose 4B.J. Clin. Chem. Clin. Biochem. 14: 475-478.

30. Fletcher, J. 1971. The plasma clearance and liver uptake of iron from transferrin of low and high iron saturation. Clin. Sci. 41: 395-402.

31. Brown, E. B., S. Okada, M. Awai, and B. Chipman. 1975. In vivo evidence for the functional heterogeneity of transferrin-bound iron. III. Studies of transferrin at high and low saturation. J. Lab. Clin. Med. 86: 576-585.

32. Lane, R. S., and C. A. Finch. 1970. The in vivo plasma clearance of iron from transferrins of low and high iron saturation. Clin. Sci. 38: 783-793.

33. Christensen, A. C., H. Huebers, and C. A. Finch. 1978.
The effect of transferrin saturation on iron delivery in rats. Am. J. Physiol. 235: R18-R22.

34. Skarberg, K., M. Eng, H. Huebers, G. Marsaglia, and C. Finch. 1978. Plasma radioiron kinetics in man. An explanation for the effect of plasma iron concentration. Proc. Natl. Acad. Sci. U. S. A. 75: 1559-1561.

35. Lane, R. S. 1973. Iron uptake by rabbit reticulocytes. Br. J. Haematol. 24: 343-353.

36. Harris, D. C., and P. Aisen. 1975. Functional equivalence of the two iron-binding sites of human transferrin. Nature (Lond.). 257: 821-823.

37. Bates, G. W., and M. R. Schlabach. 1973. The reaction of ferric salts with transferrin. J. Biol. Chem. 248: 32283232.

38. Pootrakul, P., A. Christensen, B. Josephson, and C. A. Finch. 1977. Role of transferrin in determining internal iron distribution. Blood. 49: 957-966.

39. Schade, A. L. 1964. Iron uptake by erythropoietic and other tissues from "native" serum siderophilin and from isolated "purified" siderophilin. 11 Farmaco Ed. Soc. 19: 185-202.

40. Cook, J. D., G. Marsaglia, J. W. Eschbach, D. D. Funk, and C. A. Finch. 1970. Ferrokinetics: a biologic model for plasma iron exchange in man. J. Clin. Invest. 49: 197205. 